\title{
Oxygen Breathing Affects 3'-Deoxy-3'-18 F-Fluorothymidine Uptake in Mouse Models of Arthritis and Cancer
}

\author{
Kerstin Fuchs*1,2 ${ }^{*}$ Damaris Kukuk*2, Gerald Reischl ${ }^{2}$, Michael Föller $^{3}$, Martin Eichner ${ }^{4}$, Jörg Reutershan ${ }^{5}$, Florian Lang ${ }^{3}$, \\ Martin Röcken ${ }^{1}$, Bernd J. Pichler ${ }^{2}$, and Manfred Kneilling ${ }^{1}$ \\ ${ }^{1}$ Department of Dermatology, Eberhard Karls University, Tübingen, Germany; ${ }^{2}$ Laboratory for Preclinical Imaging and Imaging \\ Technology of the Werner Siemens-Foundation, Department of Preclinical Imaging and Radiopharmacy, Eberhard Karls University, \\ Tübingen, Germany; ${ }^{3}$ Department of Physiology, Eberhard Karls University Tübingen, Tübingen, Germany; ${ }^{4}$ Department of Medical \\ Biometry, Eberhard Karls University, Tübingen, Germany; and ${ }^{5}$ Department of Anesthesiology and Intensive Care Medicine, \\ Eberhard Karls University, Tübingen, Germany
}

\begin{abstract}
Noninvasive in vivo imaging of biologic processes using PET is an important tool in preclinical studies. We observed significant differences in $3^{\prime}$-deoxy-3'-18 F-fluorothymidine ( $\left.{ }^{18} \mathrm{~F}-\mathrm{FLT}\right)$ uptake in arthritic ankles and carcinomas between dynamic and static PET measurements when mice breathed oxygen. Thus, we suspected that air or oxygen breathing and the anesthesia protocol might influence ${ }^{18} \mathrm{~F}-\mathrm{FLT}$ tracer uptake. Methods: We injected arthritic, healthy, and CT26 colon carcinoma-bearing mice with ${ }^{18} \mathrm{~F}-\mathrm{FLT}$ before static or dynamic small-animal PET measurements. The spontaneously oxygen- or air-breathing mice were kept conscious or anesthetized with ketamine and xylazine during ${ }^{18} \mathrm{~F}-\mathrm{FLT}$ uptake before the 10 -min static PET measurements. For dynamic PET scans, mice were anesthetized during the entire measurement. ${ }^{18} \mathrm{~F}-\mathrm{FLT}$ uptake was reported in percentage injected dose per cubed centimeter by drawing regions of interest around ankles, carcinomas, and muscle tissue. Additionally, venous blood samples were collected before ${ }^{18} \mathrm{~F}-\mathrm{FLT}$ injection and after PET measurement to analyze $\mathrm{pH}$, carbon dioxide partial pressure $\left(\mathrm{pCO}_{2}\right)$, and lactate values. Results: $\mathrm{A}$ significantly reduced ${ }^{18} \mathrm{~F}-\mathrm{FLT}$ uptake was measured in arthritic ankles and in CT26 colon carcinomas when the mice breathed oxygen and were conscious during tracer uptake, compared with mice that were anesthetized during ${ }^{18} \mathrm{~F}-\mathrm{FLT}$ uptake. Breathing air completely abolished this phenomenon. Analysis of blood samples that were obtained from the mice before ${ }^{18} \mathrm{~F}-\mathrm{FLT}$ injection and after the PET scan implicated respiratory acidosis that was induced by oxygen breathing and consciousness during tracer uptake. Acidosis was found to be the primary factor responsible for the reduced ${ }^{18} \mathrm{~F}$-FLT uptake, as reflected by increased $\mathrm{pCO}_{2}$ and reduced $\mathrm{pH}$ and lactate values. Conclusion: Oxygen-breathing conscious mice sustained respiratory acidosis and, consequently, reduced cell proliferation and ${ }^{18} \mathrm{~F}$-FLT uptake in arthritic ankles and CT26 colon carcinomas. Thus, we suggest the use of air instead of oxygen breathing for ${ }^{18} \mathrm{~F}-\mathrm{FLT}$ PET measurements.
\end{abstract}

Received Dec. 12, 2011; revision accepted Jan. 3, 2012

For correspondence or reprints contact: Bernd J. Pichler, Laboratory for Preclinical Imaging and Imaging Technology of the Werner Siemens-Foundation, Department of Preclinical Imaging and Radiopharmacy, Eberhard Karls University,

Röntgenweg 13, 72076 Tübingen, Germany.

E-mail: bernd.pichler@med.uni-tuebingen.de

${ }^{\star}$ Contributed equally to this work.

Published online Apr. 9, 2012.

COPYRIGHT @ 2012 by the Society of Nuclear Medicine, Inc.
Key Words: ${ }^{18} \mathrm{~F}-\mathrm{FLT}$; physiology; tumor; inflammation

J Nucl Med 2012; 53:823-830

DOI: 10.2967/jnumed.111.101808

$\mathbf{N}$ oninvasive in vivo PET of small animals can provide essential information regarding the pharmacodynamics of new therapeutic agents in mouse models of cancer and inflammation. ${ }^{18} \mathrm{~F}-\mathrm{FLT}$ is a well-known PET tracer that allows the in vivo detection of cell proliferation in the fields of cancer (1) and inflammation (2). ${ }^{18}$ F-FLT is transported by nucleoside transporters into the cell (3), where it is phosphorylated by thymidine kinase 1 to ${ }^{18} \mathrm{~F}$-FLT-monophosphate and is subsequently trapped within the cell $(4,5)$. Thymidine kinase 1 is known to be highly active during the cell cycle, particularly in the $\mathrm{S}$ and $\mathrm{G} 1$ phases (6). For in vivo PET measurement, mice need to be anesthetized and shall be maintained at a constant temperature.

Isoflurane, sevoflurane, ketamine, xylazine, medetomidine, midazolam, and pentobarbital are anesthetics that are frequently applied in rodent PET. Nevertheless, these anesthetics can impair heart function; suppress breathing frequency, blood pressure, and glucose metabolism; reduce tumor blood flow and oxygenation; and counteract inflammation (7-12).

In a preliminary study, we observed unexpected differences in ${ }^{18} \mathrm{~F}$-FLT tracer uptake in arthritic ankles between dynamic and static PET scans when the mice received ketamine and xylazine anesthesia while breathing oxygen. This finding raised the question whether air or oxygen breathing or the anesthesia protocol can influence ${ }^{18} \mathrm{~F}$-FLT uptake in experimental mouse models of inflammation and cancer. To address this question, we investigated ${ }^{18} \mathrm{~F}$-FLT uptake in the inflamed ankles of glucose-6-phosphate-isomerase (GPI) serum-injected mice (13-15) and in mice with exogenous CT26 mouse colon carcinomas $(16,17)$. Our results demonstrate that oxygen breathing and consciousness during the tracer uptake phase can reduce ${ }^{18}$ F-FLT tracer uptake. 


\section{MATERIALS AND METHODS}

\section{GPI Arthritis and CT26 Colon Carcinoma Mouse Models}

We used female BALB/c mice (Charles River Laboratories) between 8 and $12 \mathrm{wk}$ old. The experiments were conducted according to the German Animal Protection Law, and the animal use and care protocols were approved by the Regierungspräsidium Tübingen.

GPI Arthritis Model. We intraperitoneally injected naïve BALB/c mice with $100 \mu \mathrm{L}$ of either GPI or control serum on days 0 and 2 . GPI serum was obtained retrobulbarly from $\mathrm{K} / \mathrm{BxN}$ mice that were 1-3 mo old $(13,14,18)$. Control serum was obtained retrobulbarly from healthy C57BL/6 mice that were 1-6 mo old. GPI or control sera were diluted 1:1 (v/v) with saline before injection. Ankle thickness was measured with an Oditest micrometer (Kroeplin) before and at the indicated days after $\mathrm{K} / \mathrm{BxN}$ serum or control serum injection. Injecting GPI serum into BALB/c mice induced severe arthritis that was characterized by strong edema, pannus formation, and functional impairment of the joints. Maximum ankle swelling was reached by day 5 and persisted until day 7 (Supplemental Fig. 1A: supplemental materials are available online only at http://jnm.snmjournals.org). Consequently, we conducted the GPI arthritis ${ }^{18}$ F-FLT PET studies between 5 and $7 \mathrm{~d}$ after the initiation of arthritis. The histopathologic analysis of hematoxylin and eosin-stained slices of inflamed ankles $6 \mathrm{~d}$ after GPI serum injection revealed pannus formation, angiogenesis, dense infiltration of polymorphonuclear leukocytes, and joint destruction (Supplemental Fig. 3A, top). No signs of inflammation were detected in the hematoxylin- and eosin-stained slices of healthy ankles $6 \mathrm{~d}$ after control serum injection (Supplemental Fig. 3A, bottom).

CT26 Mouse Colon Carcinoma Model. Subcutaneous injection of $5 \times 10^{5}$ CT26 colon carcinoma cells into the right upper flank of $\mathrm{BALB} / \mathrm{c}$ mice induced palpable CT26 colon carcinomas within $5 \mathrm{~d}$. The diameters of the CT26 colon carcinomas were measured using a caliper. The carcinomas reached a mean volume of $204 \pm$ $30 \mathrm{~mm}^{3}$ at day 14 after CT26 colon carcinoma cell inoculation (Supplemental Fig. 1B). In vivo ${ }^{18} \mathrm{~F}$-FLT PET scans were obtained at days 10-14 after CT26 colon carcinoma cell inoculation (Supplemental Fig. 1B). The histopathologic analysis of colon carcinomas displayed viable CT26 tumors without necrotic areas (Supplemental Fig. 3B).

Although this article focuses just on investigations using ketamine and xylazine anesthesia, the animal scans were obtained within a larger study protocol with different anesthesia (supplemental material).

\section{Anesthesia}

The mice were anesthetized using a mixture of ketamine (100 $\mathrm{mg} / \mathrm{kg}$ ) (Ratiopharm) and xylazine $(5 \mathrm{mg} / \mathrm{kg}$ ) (Rompun; Bayer HealthCare), which was administered intraperitoneally in a volume of $0.1 \mathrm{~mL} / 10 \mathrm{~g}$ of body weight.

\section{Scanning Protocols and Animal Preparation}

Breathing Protocols. In the experiments, the mice breathed either $100 \%$ oxygen or air (21\% oxygen) (detailed protocols are provided in Fig. 1). We investigated the impact of breathing air or oxygen on animals under ketamine and xylazine anesthesia and the differences between ${ }^{18}$ F-FLT tracer uptake on conscious and anesthetized animals.

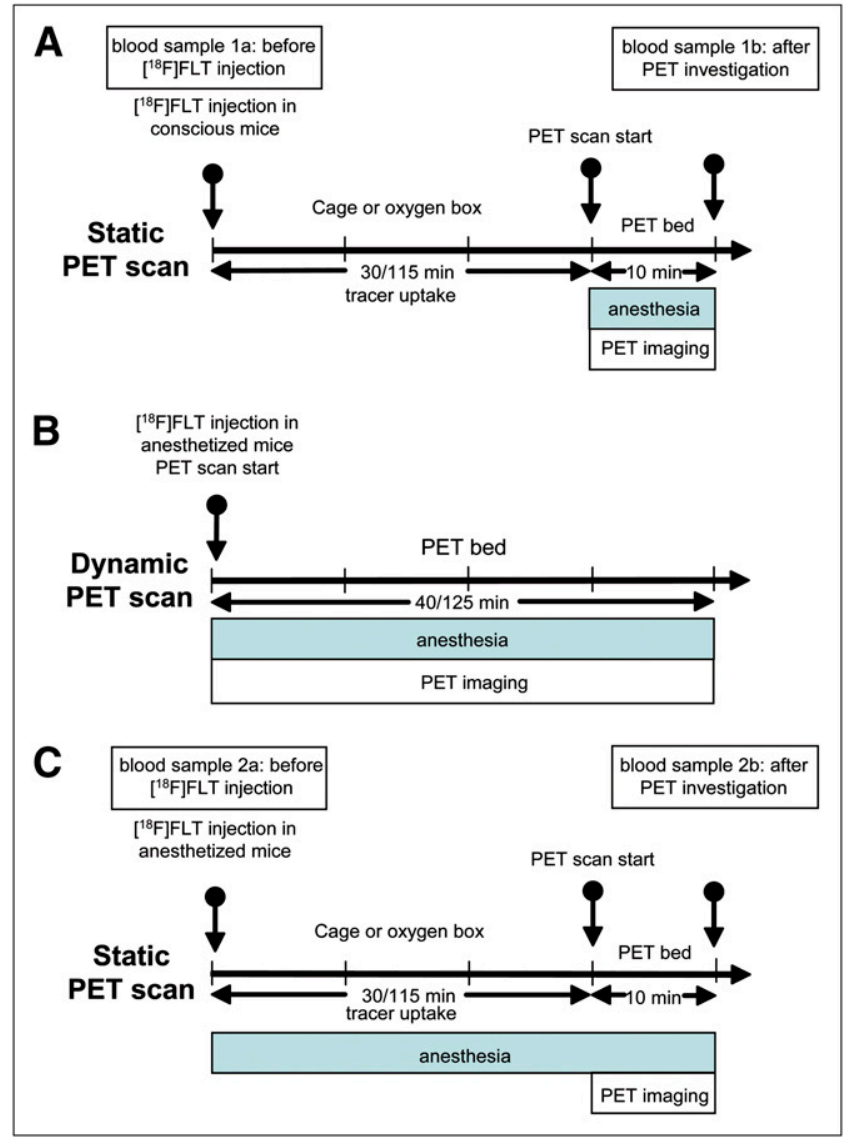

FIGURE 1. In vivo ${ }^{18} \mathrm{~F}-\mathrm{FLT}$ PET investigation protocols that were used for measurements of healthy, arthritic, and CT26 colon carcinoma-bearing mice. (A) Static PET scan protocol when mice were conscious during ${ }^{18} \mathrm{~F}-\mathrm{FLT}$ uptake. (B) Dynamic PET scan protocol when mice were anesthetized during tracer uptake. (C) Static PET scan protocol when mice were anesthetized during ${ }^{18} \mathrm{~F}-\mathrm{FLT}$ uptake. ${ }^{18} \mathrm{~F}-\mathrm{FLT}$ uptake phase was $30 \mathrm{~min}$ in arthritis or control mice and 115 min in CT26 colon carcinoma-bearing mice. Blood samples were taken at indicated time points in $\mathrm{A}$ and $\mathrm{C}$.

Tracer Injection. ${ }^{18}$ F-FLT was administered by tail vein injection using a 30-gauge needle (Becton Dickinson) that was attached to a polyethylene catheter (High-Med-PE, 0.28-mm inner diameter; Reichelt Chemietechnik). The mice were injected with $8.9 \pm$ $1.3 \mathrm{MBq}$ (arthritis) or $5.7 \pm 0.4 \mathrm{MBq}$ (CT26) of ${ }^{18}$ F-FLT mixed with isotonic saline solution at a final volume of $0.05-0.15 \mathrm{~mL}$. The catheter was flushed with $0.05 \mathrm{~mL}$ of saline after tracer injection. After the in vivo ${ }^{18}$ F-FLT PET scan, arthritic and CT26 tumor-bearing animals were sacrificed, and tissue samples were harvested for ex vivo analysis.

Static PET Scan Protocol. The mice were injected with ${ }^{18} \mathrm{~F}$ FLT, kept conscious, and allowed to move freely for $30 \mathrm{~min}$ (arthritis) or $115 \mathrm{~min}$ (CT26) in a box (100\% oxygen) or in a cage (air) during tracer uptake. After the uptake period, the mice were anesthetized for a 10-min static PET scan (Fig. 1A).

Dynamic PET Scan Protocol. The mice were anesthetized (ketamine and xylazine), placed on the bed of the PET scanner, and injected with ${ }^{18}$ F-FLT immediately after the PET data acquisition began. Additionally, a subcutaneous catheter was placed for optional 
drug application to ensure the continuation of anesthesia for at least 90-120 min (Fig. 1B). In this case, a continuous flow of $8 \mu \mathrm{L} / \mathrm{min}$ for 10 min using a syringe pump (PHD 22/2000; Harvard Apparatus) was applied.

Static PET Scan Protocol with Anesthesia During Tracer Uptake. To exclude PET scanner-specific artifacts, we mimicked the dynamic PET scan protocol, keeping the mice continuously anesthetized for $40 \mathrm{~min}$ (arthritis) or $120 \mathrm{~min}$ (CT26). The mice were placed in a temperature-controlled anesthesia box or cage until the 10-min static PET scans were acquired (Fig. 1C).

\section{Blood Sampling for Lactate, pH, and Carbon Dioxide Partial Pressure $\left(\mathrm{pCO}_{2}\right)$ Analysis}

We used 10 mice (6 arthritis and 4 control) for the arthritis model and 20 CT26 tumor-bearing mice to measure lactate, $\mathrm{pH}$, and $\mathrm{pCO}_{2}$ values. The blood samples were collected before ${ }^{18} \mathrm{~F}-$ FLT injection and after PET investigation (Figs. 1A and 1C).

Blood Sample 1a. The mice were placed in an oxygen- or airflooded box for 3-5 min before a blood sample from the retrobulbar venous plexus was collected.

Blood Sample $1 \mathrm{~b}$. Approximately $5 \mathrm{~min}$ before the end of the uptake period, the mice were anesthetized with ketamine and xylazine. A blood sample from the retrobulbar plexus was collected, directly after a 10-min static PET scan.

Blood Sample 2a. The mice were injected with ketamine and xylazine to induce anesthesia and placed in an air- or oxygenflooded box. A blood sample was taken from the retrobulbar plexus immediately after the onset of anesthesia.

Blood Sample $2 b$. A blood sample was taken from the retrobulbar plexus immediately after the end of the ${ }^{18} \mathrm{~F}$-FLT uptake time of $40 \mathrm{~min}$ (arthritis, healthy control) or $125 \mathrm{~min}$ (CT26), directly after the PET scan.

\section{Determination of Blood $\mathrm{pCO}_{2}$ and Lactate Concentration}

Blood samples of approximately $50 \mu \mathrm{L}$ were collected from the retrobulbar venous plexus at the beginning and end of the investigation, as indicated in Figures $1 \mathrm{~A}$ and $1 \mathrm{C}$ to measure blood $\mathrm{pCO}_{2}$ and lactate concentration. We measured $\mathrm{pCO}_{2}$ using a blood gas analyzer (ABL80 FLEX CO-OX; Radiometer). The lactate concentration was measured using the Accutrend Plus System (Roche) according to the manufacturer's instructions.

\section{Statistical Data Analysis}

A Dunett test was used to compare differences in the ${ }^{18} \mathrm{~F}$-FLT uptake values (in percentage injected dose per cubed centimeter $\left.\left[\% \mathrm{ID} / \mathrm{cm}^{3}\right]\right)$ in arthritic ankles between dynamic PET scans and static PET scans obtained with and without anesthesia during tracer uptake. We used the ${ }^{18} \mathrm{~F}$-FLT uptake values exclusively from the swollen arthritic ankles. For mice with 2 swollen arthritic ankles, we calculated the geometric mean of the ${ }^{18}$ F-FLT uptake values; for mice with a single swollen arthritic ankle, we used simply the ${ }^{18}$ F-FLT uptake value of that arthritic ankle for statistical analysis. The 2-tailed Student $t$ test was used to analyze the differences in ${ }^{18} \mathrm{~F}$-FLT uptake $\left(\% \mathrm{ID} / \mathrm{cm}^{3}\right)$ in the CT26 colon carcinomas between the mice that were anesthetized and the mice that were conscious during tracer uptake. Differences in lactate (in $\mathrm{mM}$ ), $\mathrm{pCO}_{2}$ (in $\mathrm{mm} \mathrm{Hg}$ ), or $\mathrm{pH}$ values between blood samples that were obtained before ${ }^{18} \mathrm{~F}$-FLT administration and after the PET investigation of arthritic, healthy, or CT26 colon carcinoma-bearing mice that were conscious or anesthetized during tracer uptake and breathed either air or oxygen were analyzed by the 2-tailed
Student $t$ test. $P$ values of less than 0.05 were considered statistically significant. All data are presented as the mean \pm SD.

\section{Experimental Groups, Cell Culture, Histology, Radiopharmaceuticals, In Vivo PET, and Data Analysis}

Please refer to the supplemental material for detailed data about the groups.

\section{RESULTS}

\section{${ }^{18}$ F-FLT Uptake in Arthritic Ankles and CT26 Colon Carcinomas}

Dynamic in vivo PET scans of ${ }^{18}$ F-FLT-injected arthritic, healthy, and CT26 colon carcinoma-bearing mice were obtained (Fig. 1B). The data were analyzed by drawing regions of interest in the ${ }^{18} \mathrm{~F}$-FLT PET images as indicated by the green circles in Supplemental Figures 2A and 2B. Time-activity curves were generated from the arthritic and healthy joints or from the CT26 colon carcinomas and muscle tissue. A peak in ${ }^{18} \mathrm{~F}$-FLT uptake was detected in the arthritic joints within $8 \mathrm{~min}$ after ${ }^{18} \mathrm{~F}$-FLT administration, followed by a slow but steady decrease over the scan time (Supplemental Fig. 2C). Healthy joints followed the same uptake curve but at a lower level. In the CT26 colon carcinomas, specific ${ }^{18}$ F-FLT uptake increased immediately after ${ }^{18}$ F-FLT injection, followed by a steady-state plateau at $60 \mathrm{~min}$ after tracer injection that lasted until the end of the PET scan (Supplemental Fig. 2D). On the basis of the tracer pharmacokinetics that were revealed in the dynamic scans, the optimal time points for the static scans (i.e., exhibiting the highest target-to-background signal) were at 30 and $115 \mathrm{~min}$ after ${ }^{18} \mathrm{~F}$-FLT injection for the GPI arthritis and CT26 colon carcinoma models, respectively.

\section{Effects of Ketamine and Xylazine Anesthesia Under Various Breathing Conditions on ${ }^{18} \mathrm{~F}$-FLT Uptake}

GPI Arthritis Model. We observed a significant $(P<$ $0.0001)$ decrease in ${ }^{18} \mathrm{~F}$-FLT uptake in dynamic (4.3 \pm $0.8 \% \mathrm{ID} / \mathrm{cm}^{3}$, anesthetized during tracer uptake) versus static $\left(2.8 \pm 0.9 \% \mathrm{ID} / \mathrm{cm}^{3}\right.$, conscious during tracer uptake) PET scans of the arthritic ankles of oxygen-breathing mice. To test whether differences in ${ }^{18}$ F-FLT uptake in arthritic ankles between dynamic and static PET measurements were a consequence of oxygen breathing, equivalent scans were obtained while the mice were breathing air. Interestingly, air breathing completely abolished the differences between the dynamic $\left(3.4 \pm 0.3 \% \mathrm{ID} / \mathrm{cm}^{3}\right)$ and static $(3.7 \pm 0.8 \%$ ID $/ \mathrm{cm}^{3}$ ) ${ }^{18}$ F-FLT PET measurements, indicating that the observed differences in ${ }^{18} \mathrm{~F}$-FLT uptake depend on oxygen breathing (Fig. 2A). To exclude any potential influences on dynamic PET measurements due to unexpected alterations caused by data acquisition (e.g., decay or dead-time correction, attenuation of mouse bed, temperature maintenance), arthritic mice anesthetized with ketamine and xylazine were placed in a temperature-controlled box during ${ }^{18} \mathrm{~F}$-FLT uptake to mimic the dynamic PET measurement conditions (Fig. 1C). We did not observe any significant differences in 


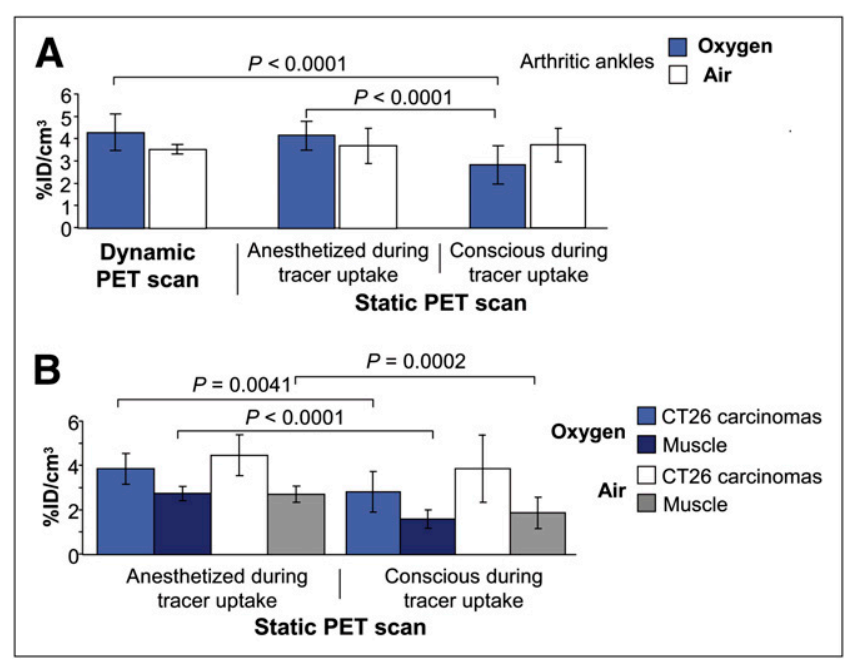

FIGURE 2. Dynamic and static ${ }^{18} \mathrm{~F}-\mathrm{FLT}$ PET scans of arthritic, healthy, and CT26 colon carcinoma-bearing mice that were anesthetized with ketamine and xylazine while breathing air (white, gray) or oxygen (blue, dark blue). (A) ${ }^{18} \mathrm{~F}-\mathrm{FLT}$ uptake was reduced in arthritic ankles during static PET scans of mice that breathed oxygen and were conscious during ${ }^{18} \mathrm{~F}-\mathrm{FLT}$ uptake (blue bars on right, $n=8$ ), compared with dynamic (blue bars on left, $n=8$ ) and static (blue bars in middle, $n=7$ ) PET scans of mice that were anesthetized during ${ }^{18} \mathrm{~F}-\mathrm{FLT}$ uptake. Static and dynamic PET scans did not differ when oxygen-breathing mice were anesthetized $(n=7)$ during entire ${ }^{18} \mathrm{~F}$-FLT uptake (blue bars on left and middle) or when mice were breathing air during ${ }^{18} \mathrm{~F}$-FLT uptake (white bars), regardless of whether there was anesthesia (GPI: $n=2-4$; control: $n=2-3$ ). Shown are mean \pm SD. Differences in ${ }^{18} \mathrm{~F}-\mathrm{FLT}$ uptake values $(\%$ $\left.\mathrm{ID} / \mathrm{cm}^{3}\right)$ in arthritic ankles were compared between dynamic and static PET scans with and without anesthesia during tracer uptake using Dunett test, with significant differences as indicated. (B) CT26 colon carcinoma-bearing mice had reduced ${ }^{18} \mathrm{~F}-\mathrm{FLT}$ uptake when they breathed oxygen and were conscious during ${ }^{18} \mathrm{~F}-\mathrm{FLT}$ uptake (blue bars on right, $n=13$ ), compared with mice that were anesthetized (blue bars on left, $n=12$ ). Air breathing abolished this effect. ${ }^{18} \mathrm{~F}$-FLT uptake was reduced in muscle tissue of both oxygen- and air-breathing mice that were anesthetized during ${ }^{18} \mathrm{~F}-\mathrm{FLT}$ uptake (dark blue bars on left), compared with the mice that were conscious (dark blue bars on right). Shown are mean \pm SD. Differences in ${ }^{18} \mathrm{~F}$-FLT uptake values $\left(\% \mathrm{ID} / \mathrm{cm}^{3}\right)$ in $\mathrm{CT} 26$ colon carcinomas between static PET scans of mice with and without anesthesia during tracer uptake were analyzed by 2-tailed Student $t$ test.

${ }^{18} \mathrm{~F}$-FLT uptake in the arthritic ankles between the mice that were placed anesthetized on the PET scanner (dynamic PET scan: air, $3.5 \pm 0.3 \% \mathrm{ID} / \mathrm{cm}^{3}$; oxygen, $4.3 \pm 0.8 \%$ $\mathrm{ID} / \mathrm{cm}^{3}$ ) and the mice that were anesthetized in a temperature-controlled box before the static PET scans (air, $3.7 \pm$ $0.7 \% \mathrm{ID} / \mathrm{cm}^{3}$; oxygen, $4.2 \pm 0.7 \% \mathrm{ID} / \mathrm{cm}^{3}$ ). This result was independent of air or oxygen breathing (Fig. 2A).

${ }^{18}$ F-FLT uptake in the healthy ankles of all of the investigated experimental groups was similar $(1.2 \pm 0.3 \% \mathrm{ID} /$ $\mathrm{cm}^{3}$ ) and was independent of air or oxygen breathing and static or dynamic PET measurements (Supplemental Fig. 4). Supplemental Figure 5A shows that the differences in ${ }^{18} \mathrm{~F}$-FLT uptake were not related to differences in ankle swelling.
CT26 Carcinoma Model. Similar to the results that were obtained in the arthritic mice, significant differences $(P=$ 0.0041) in ${ }^{18} \mathrm{~F}$-FLT uptake were observed in CT26 colon carcinomas during static PET scans when the mice were conscious $\left(2.8 \pm 0.9 \% \mathrm{ID} / \mathrm{cm}^{3}\right)$ or anesthetized with ketamine and xylazine $\left(3.9 \pm 0.7 \% \mathrm{ID} / \mathrm{cm}^{3}\right)$ and breathing oxygen during tracer uptake. Similar to the GPI arthritis model, this effect was almost completely abolished when mice were breathing air (awake during ${ }^{18} \mathrm{~F}$-FLT uptake, 3.9 $\pm 1.5 \% \mathrm{ID} / \mathrm{cm}^{3}$; anesthetized during ${ }^{18} \mathrm{~F}$-FLT uptake, $4.5 \pm$ $0.9 \% \mathrm{ID} / \mathrm{cm}^{3}$; Fig. 2B). We observed significantly reduced muscular ${ }^{18} \mathrm{~F}$-FLT uptake in the static PET scans of mice that were conscious during tracer uptake (air, $1.9 \pm 0.7 \%$ $\mathrm{ID} / \mathrm{cm}^{3}$; oxygen, $\left.1.6 \pm 0.4 \% \mathrm{ID} / \mathrm{cm}^{3}\right)$, compared with mice that were anesthetized with ketamine and xylazine (air, $2.7 \pm 0.4 \% \mathrm{ID} / \mathrm{cm}^{3}$; oxygen, $2.8 \pm 0.3 \% \mathrm{ID} / \mathrm{cm}^{3}$ ) during tracer uptake. The CT26 colon carcinomas of all experimental groups were of similar volume (Supplemental Fig. 5B).

\section{$\mathrm{pCO}_{2}$ and Lactate Formation Follows Oxygen Breathing}

Differences in ${ }^{18} \mathrm{~F}$-FLT uptake between animals that were conscious and animals that were anesthetized during tracer uptake are primarily a consequence of oxygen breathing. Because blood $\mathrm{pO}_{2}$ is an important regulator of breathing (19), breathing oxygen may reduce respiratory drive, which may in turn reduce $\mathrm{CO}_{2}$ elimination and thus facilitate the development of respiratory acidosis. Acidosis interferes with glycolysis $(20,21)$, and this might play a role in reducing inflammatory and tumor cell proliferation (22-25). To test this hypothesis, we sought to identify potential respiratory acidosis in mice under ketamine and xylazine anesthesia by analyzing $\mathrm{pH}, \mathrm{pCO}_{2}$, and lactate values in blood samples that were obtained from the retrobulbar venous plexus (as indicated in Figs. 1A and 1C) before ${ }^{18} \mathrm{~F}-$ FLT injection and at the end of static or dynamic PET.

As expected, we observed significantly increased $\mathrm{pCO}_{2}$ levels in the oxygen-breathing arthritic and CT26 carcinoma-bearing mice that were conscious during ${ }^{18} \mathrm{~F}$-FLT uptake (Figs. 3A and 3B) (arthritis: before, $45.3 \pm 4.0$ $\mathrm{mm} \mathrm{Hg}$, and after, $92.0 \pm 7.6 \mathrm{~mm} \mathrm{Hg}$; CT26: before, $53.8 \pm 11.3 \mathrm{~mm} \mathrm{Hg}$, and after, $77.2 \pm 7.5 \mathrm{~mm} \mathrm{Hg}$ ). For the mice that were anesthetized with ketamine and xylazine during ${ }^{18} \mathrm{~F}$-FLT uptake, no significant $\mathrm{pCO}_{2}$ differences were detected (Figs. 3A and 3B) (arthritis: before, 85.0 \pm $30.6 \mathrm{~mm} \mathrm{Hg}$, and after, $96.3 \pm 6.8 \mathrm{~mm} \mathrm{Hg}$; CT26: before, $66.2 \pm 8.8 \mathrm{~mm} \mathrm{Hg}$, and after, $66.4 \pm 7.6 \mathrm{~mm} \mathrm{Hg}$ ). As above, breathing air reduced this effect in the arthritic and healthy mice that were either conscious or anesthetized during ${ }^{18}$ F-FLT uptake (Fig. 3C).

As predicted, we found a significant decrease $(P=$ 0.0047) in $\mathrm{pH}$ in the blood samples that were taken from the oxygen-breathing arthritic mice that were conscious during tracer uptake, compared with blood $\mathrm{pH}$ values before ${ }^{18}$ F-FLT tracer injection (Supplemental Fig. 6A, right). 


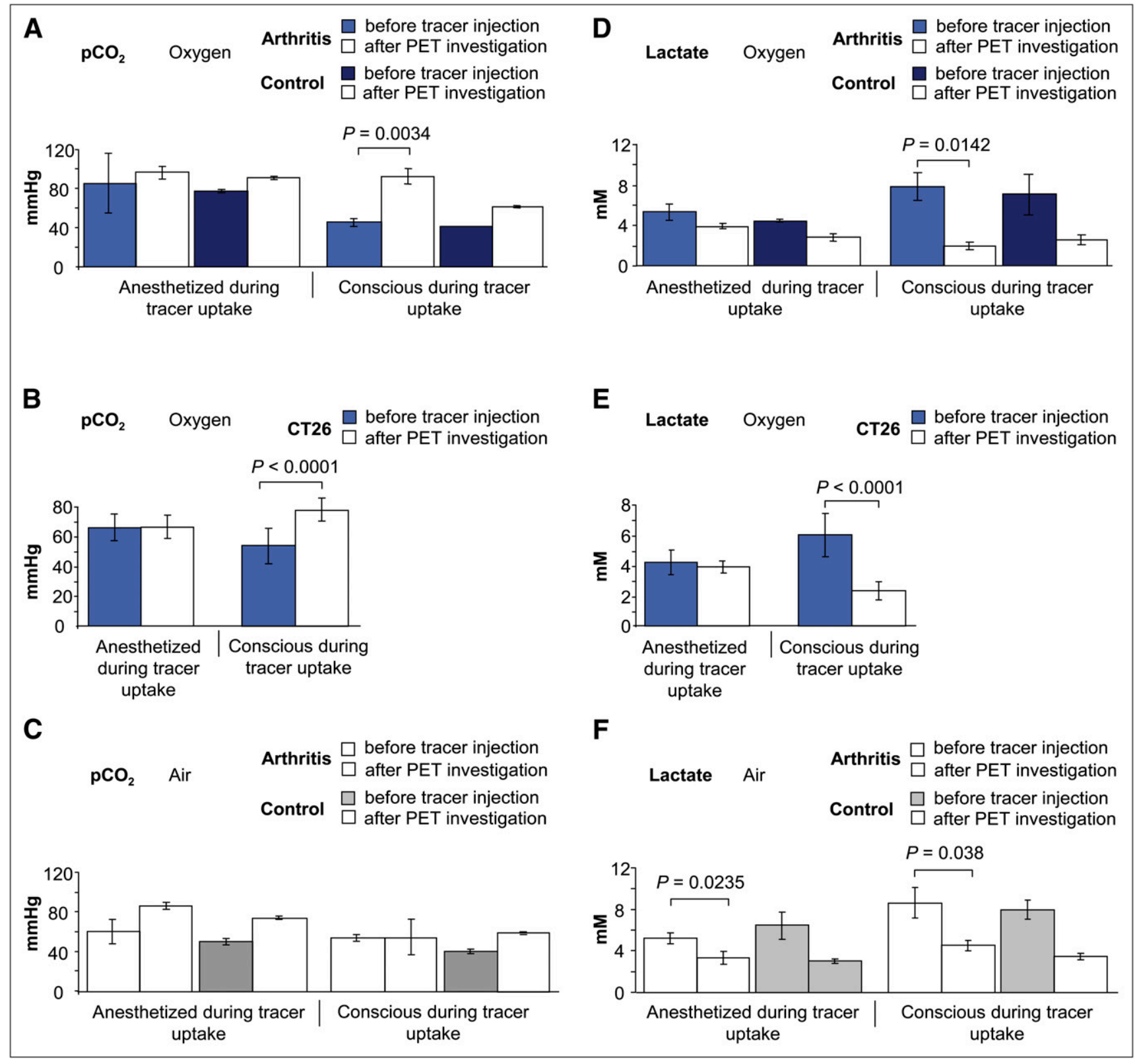

FIGURE 3. $\mathrm{pCO}_{2}$ and lactate values in healthy, arthritic, and CT26 colon carcinoma-bearing mice that were either conscious or anesthetized with ketamine and xylazine during ${ }^{18} \mathrm{~F}-\mathrm{FLT}$ uptake. (A and B) Blood samples that were obtained before ${ }^{18} \mathrm{~F}-\mathrm{FLT}$ administration and after PET investigations from oxygen-breathing, arthritic, healthy, and CT26 colon carcinoma-bearing mice that were anesthetized with ketamine and xylazine during ${ }^{18} \mathrm{~F}-\mathrm{FLT}$ uptake displayed stable $\mathrm{pCO}_{2}$ values (A and $\mathrm{B}$, left). Arthritic and CT26 colon carcinoma-bearing mice that were conscious and breathed oxygen during ${ }^{18} \mathrm{~F}-\mathrm{FLT}$ uptake had increased $\mathrm{pCO}_{2}$ values at end of investigation (A and $\mathrm{B}$, right). (C) Airbreathing arthritic and healthy control mice had similar $\mathrm{pCO}_{2}$ values when mice were either conscious or anesthetized during ${ }^{18} \mathrm{~F}-\mathrm{FLT}$ uptake. We observed trend toward increased $\mathrm{pCO}_{2}$ values in air-breathing arthritic and healthy control mice that were anesthetized with ketamine and xylazine during ${ }^{18} \mathrm{~F}-\mathrm{FLT}$ uptake $(\mathrm{C})$. Shown are mean $\pm \mathrm{SD}$. (D and E) Analysis of blood samples that were obtained before ${ }^{18} \mathrm{~F}-\mathrm{FLT}$ administration and after PET investigation revealed decrease in lactate values in arthritic $(n=3)$, healthy $(n=2)$, and CT26 colon carcinoma-bearing $(n=20)$ and oxygen-breathing mice that were conscious during ${ }^{18} \mathrm{~F}-\mathrm{FLT}$ uptake (D and E, right). In contrast, we found no decrease in lactate values in oxygen-breathing mice that were anesthetized with ketamine and xylazine during ${ }^{18} \mathrm{~F}-\mathrm{FLT}$ uptake $(\mathrm{D}$ and $\mathrm{E}$, left). (F) In arthritic air-breathing mice that were either conscious or anesthetized with ketamine and xylazine during ${ }^{18} \mathrm{~F}-\mathrm{FLT}$ uptake, we revealed decrease in lactate values.

Importantly, a slighter but qualitatively similar decrease was also detected in blood samples that were obtained from oxygen-breathing control mice, thereby allowing us to discount the influence of the inflammatory stimulus. This decrease in arthritic and control mice was abolished in air-breathing mice that were conscious during tracer uptake (Supplemental Fig. 6B, right). Arthritic mice and healthy control mice that were anesthetized with ketamine and xylazine during ${ }^{18} \mathrm{~F}-$ 
FLT uptake and oxygen breathing had a slight decrease in $\mathrm{pH}$ that did not reach the level of significance between blood samples that were obtained before ${ }^{18} \mathrm{~F}$-FLT injection and blood samples obtained at the end of the PET scan (Supplemental Fig. 6A, left). Interestingly, we detected a significant decrease $(P=0.0491)$ in blood $\mathrm{pH}$ in the arthritic mice that breathed air and were anesthetized with ketamine and xylazine during ${ }^{18} \mathrm{~F}$-FLT uptake, compared with $\mathrm{pH}$ values before ${ }^{18} \mathrm{~F}$-FLT tracer injection (Supplemental Fig. 6B, left), matching our hypothesis and ${ }^{18} \mathrm{~F}$-FLT uptake results.

The CT26 colon carcinoma-bearing oxygen-breathing mice that were examined in the same context yielded results nearly identical to those for the arthritic and healthy control mice and yielded significant differences $(P=0.0016)$ in terms of blood $\mathrm{pH}$ (Supplemental Fig. 6C, right) after the PET scans, in mice with a conscious tracer uptake, compared with blood $\mathrm{pH}$ values before ${ }^{18} \mathrm{~F}$-FLT tracer injection. Mice that were anesthetized with ketamine and xylazine for 125 min during ${ }^{18} \mathrm{~F}$-FLT uptake exhibited no significant changes in blood $\mathrm{pH}$ after PET investigations, compared with $\mathrm{pH}$ values before tracer injection (Supplemental Fig. 6C, left), confirming again the imaging results and our hypothesis.

Impaired glycolysis is expected to affect lactate formation (21). Therefore, blood samples were obtained as described previously (Figs. 1A and 1C). Consistent with decreased blood pH (Supplemental Fig. 6), we observed a significant decrease in blood lactate levels in arthritic, control, and CT26 colon carcinoma-bearing mice that were conscious and breathing oxygen during ${ }^{18} \mathrm{~F}$-FLT uptake (Figs. 3D and 3E) (arthritis: before, $7.8 \pm 1.3 \mathrm{mM}$, and after, $1.9 \pm 0.4 \mathrm{mM}$; control: before, $7.1 \pm 2.0 \mathrm{mM}$, and after, $2.6 \pm 0.5 \mathrm{mM}$; CT26: before, $6.0 \pm 1.4 \mathrm{mM}$, and after, $2.3 \pm 0.6 \mathrm{mM}$ ). In contrast, only minor differences in blood lactate values were found when mice were anesthetized with ketamine and xylazine for 40-125 min during ${ }^{18} \mathrm{~F}$-FLT uptake. These differences might be a consequence of an approximately $30 \%$ reduction in lactate levels due to anesthesia induction at the beginning of the investigation (Figs. 3D, left, and 3E, left) (arthritis: before, $5.3 \pm$ $0.8 \mathrm{mM}$, and after, $3.8 \pm 0.2 \mathrm{mM}$; control: before, $4.4 \pm 0.1$ $\mathrm{mM}$, and after, $2.8 \pm 0.4 \mathrm{mM}$; CT26: before, $4.3 \pm 0.4 \mathrm{mM}$, and after, $3.9 \pm 0.4 \mathrm{mM}$ ). Breathing air reduced this effect in the arthritic and healthy mice that were conscious during ${ }^{18}$ F-FLT uptake (Fig. 3F, right). Despite the reduced effect in the air-breathing arthritic mice that were conscious or anesthetized during ${ }^{18} \mathrm{~F}$-FLT uptake, we detected a significant decrease in lactate values between blood samples that were obtained before ${ }^{18} \mathrm{~F}$-FLT injection and blood samples that were obtained after the PET investigation (Fig. 3F). Because this effect was present in both air-breathing experimental groups, arthritic ankles and CT26 colon carcinomas, no differences in ${ }^{18} \mathrm{~F}$-FLT-uptake were detectable.

\section{DISCUSSION}

Only a few studies have investigated the impact of anesthesia and breathing protocols on radiotracer uptake in animal imaging experiments (11). The choice of breathing gas (i.e., air or oxygen) and the anesthesia protocol can affect the reproducibility and reliability of PET studies; thus, these parameters should be selected carefully before the onset of a new research project. Therefore, knowledge regarding the impact of anesthetics, varying anesthesia duration, and use of air or oxygen breathing on the physiologic parameters of laboratory animals is crucial to allow comparisons to be made among imaging studies from various laboratories and to avoid conducting unnecessary animal experiments.

With 10-min static PET scans under ketamine and xylazine anesthesia performed on oxygen-breathing mice that were conscious during tracer uptake, we detected a significant reduction in tracer uptake of $34 \%$ in arthritic ankles and of $27 \%$ in CT26 colon carcinomas, when compared with mice that were anesthetized during the entire tracer uptake period. Breathing air abolished this phenomenon in mice of both experimental models, yielding stable tracer uptake conditions that were independent of whether the mice were anesthetized or awake.

Interestingly, ${ }^{18} \mathrm{~F}-\mathrm{FLT}$ uptake in the muscle tissue of CT26 colon carcinoma-bearing mice that were anesthetized during tracer uptake was significantly higher than in mice that were conscious during tracer uptake, regardless of whether they were breathing air or oxygen (air, $P=0.0002$; oxygen, $P<0.0001$ ).

Consciousness and oxygen breathing reduce ${ }^{18} \mathrm{~F}$-FLT uptake in static scans with 15-20 min of short-term anesthesia in both experimental models, compared with measurements applying 40- to 120-min long-term anesthesia. Therefore, we focused further on the impact of breathing oxygen on ${ }^{18} \mathrm{~F}$-FLT uptake, because oxygen seemed to be the primary responsible factor for reduced cell proliferation.

In mice that are conscious during ${ }^{18} \mathrm{~F}-\mathrm{FLT}$ tracer uptake, we expect a normal breathing frequency and depth of respiration. In contrast, anesthesia reduces the breathing frequency and respiration volume. Furthermore, an increasing depth of anesthesia correlates with a reduction in breathing frequency and tidal ventilation (26). Compared with mice that were conscious during tracer uptake, a consequence of anesthesia is a decreased oxygen supply in carcinomas and inflamed tissues, because the cardiovascular system is decelerated.

Oxygen consumption is dependent on partial pressure of oxygen and yields changes in tissue $\mathrm{pH}$ (19). Oxygen plays a critical role in wound healing by blocking the proliferation of inflammatory cells (27-29) and increasing adenosine triphosphate degradation (30). Moreover, breathing oxygen may decrease blood flow in tumors as a consequence of vasoconstriction $(31,32)$. At least in theory, an increase of $\mathrm{O}_{2}$ pressure could thus compromise $\mathrm{CO}_{2}$ uptake by erythrocytes in peripheral tissues and thus favor the development of tissue acidosis. Erythrocyte $\mathrm{O}_{2}$ and $\mathrm{CO}_{2}$ transport interact by the Bohr and Haldane effects (33). Deoxygenation of hemoglobin fosters binding $\mathrm{CO}_{2}$ and $\mathrm{H}^{+}$(Haldane effect), and 
conversely, binding of $\mathrm{CO}_{2}$ and $\mathrm{H}^{+}$decreases $\mathrm{O}_{2}$ affinity (Bohr effect). Similar to anesthesia, oxygen breathing can reduce the breathing frequency in both conscious and anesthetized mice. Consequently, reduced breathing frequency due to oxygen breathing and anesthesia may compromise $\mathrm{CO}_{2}$ elimination and lead to respiratory acidosis. Respiratory acidosis leads, in turn, to cellular acidification, which is a powerful inhibitor of glycolysis (21) and is therefore expected to inhibit cell proliferation (22-25). To test this hypothesis, we used ketamine and xylazine anesthesia and analyzed $\mathrm{pCO}_{2}, \mathrm{pH}$, and lactate values in blood samples that were obtained from the retrobulbar venous plexus before ${ }^{18} \mathrm{~F}$-FLT administration and at the end of PET investigation (Supplemental Fig. 1).

The $\mathrm{pCO}_{2}$ values in the oxygen-breathing mice that were conscious during ${ }^{18} \mathrm{~F}$-FLT uptake increased significantly over the observation period, whereas they remained constant in mice that were anesthetized during tracer uptake. This finding confirms that oxygen breathing made the respiratory acidosis significantly worse, possibly causing impaired cell proliferation. In contrast, such an effect was not seen in air-breathing mice (Fig. 3). Moreover, $\mathrm{pH}$ and lactate values decreased significantly in oxygen-breathing mice that were kept conscious during ${ }^{18} \mathrm{~F}$-FLT uptake and were anesthetized only for 10-min static PET measurements. However, lactate values were initially lower in the anesthetized oxygen-breathing animals before the uptake phase and remained constant during the entire anesthesia time. Interestingly, the lowest value that was found in the oxygen-breathing mice that were awake during the uptake $(1.9 \pm 0.4 \mathrm{mM})$ corresponds to the lowest ${ }^{18} \mathrm{~F}$-FLT uptake in the same study groups (Fig. 2). This finding explains why anesthetized oxygen-breathing mice had higher ${ }^{18} \mathrm{~F}-\mathrm{FLT}$ uptake, because they are better protected from respiratory and metabolic acidosis than conscious oxygen-breathing mice, perhaps due to an anesthesia-induced initial decrease in breathing frequency and tidal volume. Furthermore, acidosis compromises glycolysis, which is apparent from the decline in plasma lactate values. This impaired glucose utilization is expected to inhibit cell proliferation and consequently ${ }^{18} \mathrm{~F}$-FLT uptake in inflamed tissue and carcinomas. Our results are of special importance for preclinical ${ }^{18} \mathrm{~F}$-FLT studies not only because of a reduction in ${ }^{18} \mathrm{~F}$-FLT uptake in carcinomas or metastasis but also because a consequence of respiratory or metabolic acidosis could be evident in patients with obstructive lung disease, asthma, or ketoacidosis.

\section{CONCLUSION}

Our PET studies clearly indicate that the primary factors influencing ${ }^{18} \mathrm{~F}$-FLT uptake in arthritis and carcinomas are based on air or oxygen breathing and on whether the mice are conscious or anesthetized during tracer uptake. The most reliable and reproducible ${ }^{18} \mathrm{~F}-\mathrm{FLT}$ uptake results among the various PET scan protocols were achieved with air-breathing conditions. Oxygen breathing and consciousness during ${ }^{18} \mathrm{~F}$-FLT uptake sustained respiratory acidosis reflected by increased $\mathrm{pCO}_{2}$ and reduced $\mathrm{pH}$ and lactate values. Thus, acidosis impairs glucose utilization, cell proliferation, and consequently ${ }^{18}$ F-FLT uptake in inflamed tissue and carcinomas. Therefore, to avoid reduced ${ }^{18} \mathrm{~F}-\mathrm{FLT}$ uptake due to acidosis, we suggest the use of air breathing.

\section{DISCLOSURE STATEMENT}

The costs of publication of this article were defrayed in part by the payment of page charges. Therefore, and solely to indicate this fact, this article is hereby marked "advertisement" in accordance with 18 USC section 1734.

\section{ACKNOWLEDGMENTS}

We thank Maren Koenig, Mareike Lehnhoff, Daniel Bukala, Nadine Bauer, and Stefan Wiehr for excellent technical and practical assistance. This work was supported by the Deutsche Forschungsgemeinschaft (SFB 773), the Bundesministerium für Bildung und Forschung (BMBF, FKZ 0314103), and the Werner Siemens-Foundation. No other potential conflict of interest relevant to this article was reported.

\section{REFERENCES}

1. Been LB, Suurmeijer AJ, Cobben DC, Jager PL, Hoekstra HJ, Elsinga PH. $\left[{ }^{18} \mathrm{~F}\right]$ FLT-PET in oncology: current status and opportunities. Eur J Nucl Med Mol Imaging. 2004;31:1659-1672.

2. van Waarde A, Jager PL, Ishiwata K, Dierckx RA, Elsinga PH. Comparison of sigma-ligands and metabolic PET tracers for differentiating tumor from inflammation. J Nucl Med. 2006;47:150-154.

3. Paproski RJ, Ng AM, Yao SY, Graham K, Young JD, Cass CE. The role of human nucleoside transporters in uptake of $3^{\prime}$-deoxy-3'-fluorothymidine. Mol Pharmacol. 2008;74:1372-1380.

4. Dimitrakopoulou-Strauss A, Strauss LG. The role of ${ }^{18} \mathrm{~F}$-FLT in cancer imaging: does it really reflect proliferation? Eur J Nucl Med Mol Imaging. 2008;35: 523-526.

5. Shields AF, Grierson JR, Dohmen BM, et al. Imaging proliferation in vivo with [F-18]FLT and positron emission tomography. Nat Med. 1998;4:1334-1336.

6. Krohn KA, Mankoff DA, Eary JF. Imaging cellular proliferation as a measure of response to therapy. J Clin Pharmacol. 2001;suppl:96S-103S.

7. Cullen BM, Walker HC. The effect of several different anaesthetics on the blood pressure and heart rate of the mouse and on the radiation response of the mouse sarcoma RIF-1. Int J Radiat Biol Relat Stud Phys Chem Med. 1985;48:761-771.

8. Zanelli GD, Lucas PB, Fowler JF. The effect of anaesthetics on blood perfusion in transplanted mouse tumours. Br J Cancer. 1975;32:380-390.

9. Menke H, Vaupel P. Effect of injectable or inhalational anesthetics and of neuroleptic, neuroleptanalgesic, and sedative agents on tumor blood flow. Radiat Res. 1988;114:64-76.

10. Flores JE, McFarland LM, Vanderbilt A, Ogasawara AK, Williams SP. The effects of anesthetic agent and carrier gas on blood glucose and tissue uptake in mice undergoing dynamic FDG-PET imaging: sevoflurane and isoflurane compared in air and in oxygen. Mol Imaging Biol. 2008;10:192-200.

11. Fueger BJ, Czernin J, Hildebrandt I, et al. Impact of animal handling on the results of ${ }^{18}$ F-FDG PET studies in mice. J Nucl Med. 2006;47:999-1006.

12. Reutershan J, Chang D, Hayes JK, Ley K. Protective effects of isoflurane pretreatment in endotoxin-induced lung injury. Anesthesiology. 2006;104:511-517.

13. Kouskoff V, Korganow AS, Duchatelle V, Degott C, Benoist C, Mathis D. Organspecific disease provoked by systemic autoimmunity. Cell. 1996;87:811-822.

14. Kneilling M, Hultner L, Pichler BJ, et al. Targeted mast cell silencing protects against joint destruction and angiogenesis in experimental arthritis in mice. Arthritis Rheum. 2007;56:1806-1816.

15. Monach $\mathrm{P}$, Hattori $\mathrm{K}$, Huang $\mathrm{H}$, et al. The $\mathrm{K} / \mathrm{BxN}$ mouse model of inflammatory arthritis: theory and practice. Methods Mol Med. 2007;136:269-282.

16. Brattain MG, Strobel-Stevens J, Fine D, Webb M, Sarrif AM. Establishment of mouse colonic carcinoma cell lines with different metastatic properties. Cancer Res. 1980;40:2142-2146. 
17. Ziegler A, Heidenreich R, Braumuller H, et al. EpCAM, a human tumor-associated antigen promotes Th2 development and tumor immune evasion. Blood. 2009;113:3494-3502.

18. Monach PA, Mathis D, Benoist C. The $\mathrm{K} / \mathrm{BxN}$ arthritis model. Curr Protoc Immunol. 2008; chapter 15:unit 15.22.

19. Acker H. PO2 chemoreception in arterial chemoreceptors. Annu Rev Physiol. 1989;51:835-844.

20. Arnett TR. Acidosis, hypoxia and bone. Arch Biochem Biophys. 2010;503: 103-109.

21. Boiteux A, Hess B. Design of glycolysis. Philos Trans R Soc Lond B Biol Sci. 1981;293:5-22.

22. Brahimi-Horn MC, Bellot G, Pouyssegur J. Hypoxia and energetic tumour metabolism. Curr Opin Genet Dev. 2011;21:67-72.

23. Izumi $\mathrm{H}$, Torigoe $\mathrm{T}$, Ishiguchi $\mathrm{H}$, et al. Cellular $\mathrm{pH}$ regulators: potentially promising molecular targets for cancer chemotherapy. Cancer Treat Rev. 2003;29: 541-549.

24. Lang F, Foller M, Lang KS, et al. Ion channels in cell proliferation and apoptotic cell death. J Membr Biol. 2005;205:147-157.

25. Vaupel P. Tumor microenvironmental physiology and its implications for radiation oncology. Semin Radiat Oncol. 2004;14:198-206.
26. Hikasa Y, Ohe N, Takase K, Ogasawara S. Cardiopulmonary effects of sevoflurane in cats: comparison with isoflurane, halothane, and enflurane. Res Vet Sci. 1997;63: 205-210.

27. Kalliainen LK, Gordillo GM, Schlanger R, Sen CK. Topical oxygen as an adjunct to wound healing: a clinical case series. Pathophysiology. 2003;9:81-87.

28. Komoto Y, Nakao T, Sunakawa M, Yorozu H. Elevation of tissue PO2 with improvement of tissue perfusion by topically applied CO2. Adv Exp Med Biol. 1988;222:637-645.

29. LaVan FB, Hunt TK. Oxygen and wound healing. Clin Plast Surg. 1990;17:463-472.

30. Chen Y, Cairns R, Papandreou I, Koong A, Denko NC. Oxygen consumption can regulate the growth of tumors, a new perspective on the warburg effect. PLoS ONE. 2009;4:e7033.

31. Kruuv J, Inch WR, McCredie JA. Effects of breathing gases containing oxygen and carbon dioxide at 1 and 3 atmospheres pressure on blood flow and oxygenation of tumors. Can J Physiol Pharmacol. 1967;45:49-56.

32. Tozer GM, Penhaligon M, Nias AH. The use of ketamine plus diazepam anaesthesia to increase the radiosensitivity of a $\mathrm{C} 3 \mathrm{H}$ mouse mammary adenocarcinoma in hyperbaric oxygen. Br J Radiol. 1984;57:75-80.

33. Jensen FB. Red blood cell pH, the Bohr effect, and other oxygenation-linked phenomena in blood O2 and CO2 transport. Acta Physiol Scand. 2004;182:215-227.

\section{Erratum}

In the article "Recombinant Human Thyroid-Stimulating Hormone Versus Thyroid Hormone Withdrawal in the Identification of Metastasis in Differentiated Thyroid Cancer with ${ }^{131}$ I Planar Whole-Body Imaging and ${ }^{124}$ I PET," by Van Nostrand et al. ( $\mathrm{Nucl} \mathrm{Med.} \mathrm{2012;53:359-362),} \mathrm{the} \mathrm{unit} \mathrm{of} \mathrm{measure} \mathrm{stated} \mathrm{for} \mathrm{urinary} \mathrm{iodine} \mathrm{in} \mathrm{Table} 2$ was incorrect. The correct unit is $\mu \mathrm{g} / \mathrm{L}$. The authors regret the error. 